\title{
TEORIAS DAS PRÁTICAS: ANÁLISE DA ADOÇÃO DE PRÁTICAS SOCIOAMBIENTAIS EM UM PROGRAMA PÚBLICO
}

\author{
Aline Ribeiro Gomes \\ Mestranda em Administração e Controladoria \\ Universidade Federal do Ceará Fortaleza - CE - Brasil \\ alinearg@gmail.com https://orcid.org/0000-0002-9556-3353 \\ José Carlos Lázaro da Silva Filho \\ Doutor em Planejamento Ambiental \\ Universidade Federal do Ceará Fortaleza - CE - Brasil \\ lazaro.ufc@gmail.com http://orcid.org/0000-0002-8227-5491 \\ Áurio Lúcio Leocádio \\ Pós-doutorando em Gestão Internacional \\ Universidade Federal do Ceará Fortaleza - CE - Brasil \\ aurioleocadio42@gmail.com http://orcid.org/0000-0003-3175-3382
}

\begin{abstract}
RESUMO
Crescentes são as cobranças da sociedade para que as organizações atentem a modelos socioambientais, sobretudo na utilização de recursos. Para que os princípios sustentáveis sejam adotados nas atividades cotidianas da gestão pública, fazem-se necessárias mudanças de atitudes e práticas, de forma a minimizar os impactos sociais e ambientais dessas atividades. Diante do contexto apresentado, este artigo tem como objetivo investigar, por meio de uma pesquisa qualitativa, a adesão dos colaboradores de um órgão público às práticas da $\mathrm{A} 3 \mathrm{P}$ referentes ao uso do recurso energia promovidas na instituição analisada. Nesse intuito, foram utilizadas as lentes das Teorias das Práticas aplicadas por Shove, Pantzar e Watson (2012), onde as práticas são simplificadas nos elementos culturais compartilhados: material, significado e conhecimento prático/competência. Dos resultados obtidos, pode-se constatar que, das três práticas referentes ao uso racional da energia detectadas, uma demonstra deficiência do elemento material e as outras duas apresentam os três elementos constituintes das práticas. Assim, os resultados apontaram para a necessidade de se trabalhar o elemento material em uma das práticas sustentáveis analisadas, de forma que essa se estabeleça na instituição. O modelo aplicado por Shove et al. (2012) poderá ser utilizado como referência de análise em novos estudos.
\end{abstract}

Palavras-chave: A3P - Agenda Ambiental na Administração Pública. Desenvolvimento sustentável. Práticas socioambientais. Teorias das práticas.

\section{PRACTICE THEORIES: ANALYSIS OF THE ADOPTION OF SOCIO-ENVIRONMENTAL PRACTICES IN A PUBLIC PROGRAM}

\begin{abstract}
Society's demands for organizations to pay attention to socio-environmental models are growing, especially in the use of resources. The adoption of sustainable principles in public management activities requires changes in attitudes and practices to minimize their social and environmental impacts. To that end, this paper aims to investigate the adherence of employees of a public organization to the $\mathrm{A} 3 \mathrm{P}$ practices related to the use of energy resources promoted in the analyzed institution through qualitative research. We used the Lenses of Practice Theories applied by Shove, Pantzar and Watson (2012), where practices are simplified in the shared cultural elements: material, me aning and practical knowledge/competence. The findings of the research indicated three practices related to the rational use of energy, which was identified that one demonstrates deficiency of the material element and the other two present the three constituent elements of the practices. Thus, the results pointed out the need to work the material element in one of the sustainable practices analyzed, so that it can be established in the institution. The model applied by Shove et al. (2012) may be used as a reference for analysis in further studies.
\end{abstract}

Key words: A3P - Environmental Public Administration Agenda. Practice theories. Socio-environmental practices. Sustainable development.

Data da submissão: $12 / 12 / 2019$

Data de aceite: 09/03/2020 
Teorias das práticas: análise da adoção de práticas socioambientais em um programa público

\section{INTRODUÇÃO}

Desde o início da década de 1970, a humanidade vem percebendo um novo paradigma de desenvolvimento. Na publicação Our Common Future (Nosso Futuro Comum), em 1988, a Organização das Nações Unidas (ONU) registra a situação ambiental e social global, define o conceito de Desenvolvimento Sustentável como objetivo global de desenvolvimento e estabelece uma confirmação desse novo paradigma (Seebode, Jeanrenaud, \& Bessant, 2012).

Diante desse novo paradigma, a sociedade, cada vez mais se atenta aos efeitos negativos decorrentes dos sistemas produtivos, passa a ter posturas mais ativas de cobrança às organizações, sejam elas públicas ou privadas, para que estas incorporem práticas socioambientais em suas atividades e seus processos (Rosa, Gomes, Barbieri, Rodrigues, \& Kneipp, 2019). Na esfera pública, essas pressões obrigam à tomada de medidas por parte do Estado com fins de alinhamento aos propósitos sustentáveis (Silva, Betiol, Villac, \& Nonato, 2018), uma vez que as organizações públicas se comportam como grandes consumidoras de bens e serviços (Ministério do Meio Ambiente, 2009).

Autores que estudam as políticas públicas visando a sustentabilidade perceberam que uma abordagem normativa de adoção do objetivo global de sustentabilidade apresenta problema de aderência ampla. Isto pode ser entendido, visto sua complexidade perante as diversidades culturais e a percepção do problema no nível individual e no nível político nacional (Spaargaren, 2013).

Normativamente, o caminho mais viável de conciliação das "[...]demandas mundiais pelos recursos naturais e sua capacidade de suprimento é o consumo e produção sustentáveis, que consiste no Objetivo de Desenvolvimento Sustentável 12 [ODS 12]", como alertam Palhares et al. (2018, p.13). Esta iniciativa do Programa das Nações Unidas para o Meio Ambiente [Pnuma] (2012, p.12) explana que "[...] o consumo e a produção sustentável trata da promoção da eficiência energética e de recurso, bem como de uma infraestrutura sustentável, do acesso a serviços básicos, empregos verdes e decentes e de uma melhor qualidade de vida para todos".

No Brasil, consoante o Ministério do Meio Ambiente [MMA] (2011), existe um Plano de Ação para Produção e Consumo Sustentáveis [Ppcs] com o propósito de direcionar o País na busca de padrões de consumo e produção com sustentabilidade. Dentre as prioridades do PPCS, focando as organizações públicas, encontra-se a Agenda Ambiental na Administração Pública [A3P], que busca estimular nos gestores públicos a adoção de princípios e critérios de gestão ambiental na sua rotina de atividade, proporcionando, dessa forma, economia de recursos naturais e redução de gastos institucionais por meio do uso racional dos bens públicos e da gestão dos resíduos (MMA, 2009). A proposta do PPCS institui normativamente ações para as empresas públicas se engajarem para a Sustentabilidade, no entanto, pouco se analisa sobre o processo de implementação, ou seja, a adoção desta inovação organizacional que engloba novas tecnologias (luzes, ares condicionados, interruptores) e novas práticas sociais, ligadas ou não aos artefatos tecnológicos.

Nota-se que um dos objetos centrais de Transição Sociotécnica para Sustentabilidade [TSpS] é a geração e o consumo de energia, elétrica ou primária, pois atualmente a maior problemática ambiental coletiva global são as Mudanças Climáticas provocadas pelo aquecimento antropocêntrico da temperatura da biosfera, causado pela queima de combustíveis fósseis na geração de energia. E recentemente os estudos de transição têm trazido a discussão sobre a limitação da abordagem usualmente utilizada, da Perspectiva MultiNível (Multi-Level Pesrpective [MLP]) (Avelino \& Wittmayer, 2016), sendo uma das alternativas de abordagem a das Práticas Sociais (Cohen, Brown, \& Vergragt, 2013; Grin et al., 2011).

Apesar do uso comum do termo "práticas" no sentido de ação ou aplicação empírica, na Sociologia e nos Estudos Organizacionais, analisar as "práticas" pode ser considerado uma nova lente epistemológica. Para estudar as "práticas", parte dos estudos organizacionais (Bispo, 2013) tem utilizado uma visão complementar à abordagem racional, a abordagem das Práticas, que emergiu com autores da sociologia, tais como Bourdieu (2011) e Giddens (1984), sendo aprofundada ultimamente por Theodore Schatzki (2005a, 2005b) e outros autores, tais como 
Gherardi (2013) e Nicolini $(2012,2017)$. Um dos poucos consensos sobre as abordagens das Práticas é sua diversidade, que não se unifica em uma única Teoria. As "práticas", como rotinas não racionalizadas, são então interpretadas com um conjunto de elementos constituintes que possibilitam ou viabilizam sua execução (Reckwitz, 2002).

A despeito de uma discussão epistemológica sobre o uso desta abordagem com um viés pragmático, autores que vêm estudando as práticas no consumo em geral (Warde, 2005) e, especificamente, mais ambientalmente adequadas para uma humanidade mais sustentável (Spaargaren, 2011) simplificaram os elementos das práticas em três grandes conjuntos de elementos constituintes, conforme Shove et al. (2012) e Spurling et al. (2013), quais sejam, material, significado (means) e competência/conhecimento prático (skill). Aqui entende-se que uma análise das práticas sustentáveis e a ausência das práticas normativamente estabelecidas podem ser analisadas pragmaticamente como Spurling et al. (2013) e Süßbauer e Schäfer (2018) fizeram sobre intervenções, considerando a normalização e o desejo do órgão como uma intervenção .

Diante das considerações expostas, buscou-se responder a questão de pesquisa deste artigo: Como se dá a adoção de novas práticas de uso do recurso energia por parte dos colaboradores de um órgão da administração pública? O objetivo geral desta pesquisa é investigar a adesão dos colaboradores da Fundação Núcleo de Tecnologia Industrial do Ceará [Nutec] às práticas da A3P, referentes ao uso da energia promovidas na instituição, usando as lentes das Teorias das Práticas aplicadas por Shove et al. (2012).

Como justificativa central do trabalho, está a lacuna explicativa sobre as falhas na implementação do Programa A3P, estabelecido há vinte anos no Brasil, consonante ao pouco uso das lentes das práticas para entender estas lacunas. Na Europa, desde 2013, alguns autores, tais como Tom Hargreaves (2011), Gerd Spaargaren (2011, 2013), vem discutindo esta nova abor dagem para entender as falhas de políticas europeias (normativas racionais) propostas para contribuir com a Sustentabilidade. Hargreaves (2011) pesquisa um programa muito similar ao A3P.

Este estudo se divide em cinco seções e se inicia com a introdução, na segunda seção apresenta referencial teórico, na terceira seção trata da metodologia. Posteriormente, apresenta a análise e discussões dos resultados obtidos e, por fim, aborda as considerações finais.

\section{FUNDAMENTAÇÃO TEÓRICA}

Esta seção explora as bases teóricas concernentes à Agenda Ambiental na Administração Pública [A3P] e às Teorias das Práticas [TdP].

\subsection{Agenda Ambiental na Administração Pública [A3P]}

A A3P é um projeto do MMA surgido em 1999 com o intuito de revisão dos padrões produtivos e de consumo e da adoção de novos referenciais de sustentabilidade ambiental nas instituições da administração pública (MMA, 2009, 2013). Suas diretrizes, segundo o MMA (2009), são fundamentadas nas recomendações do Capítulo IV da Agenda 21, que orienta aos países a concepção de programas que se preocupem com a análise dos padrões insustentáveis de produção e consumo e a elaboração de políticas e estratégias nacionais que estimulem mudanças nesses padrões (Federal, 1995).

Consoante o MMA (2013), a A3P objetiva despertar nos servidores o senso reflexivo perante os critérios de gestão socioambiental e a consequente mudança de atitude e incorporação desses critérios nas suas atividades diárias. Além disso, são pretensões da A3P (MMA, 2013):

a) Sensibilização dos gestores públicos no tocante às questões socioambientais;

b) Promoção da utilização racional dos recursos naturais e redução de gastos na instituição;

c) Contribuição para que ocorra a revisão dos padrões produtivos e de consumo e para a adesão à novos referenciais de sustentabilidade na esfera da administração pública; 
Teorias das práticas: análise da adoção de práticas socioambientais em um programa público

d) Redução do impacto socioambiental negativo direto e indireto gerado no cumprimento das atividades administrativas e operacionais;

e) Contribuição para a melhoria da qualidade de vida.

Com o intuito de atingir essas pretensões, a Agenda Ambiental na Administração Pública foi estruturada em cinco eixos temáticos prioritários constituídos por ações que visam a redução dos impactos socioambientais negativos (Figura 1):

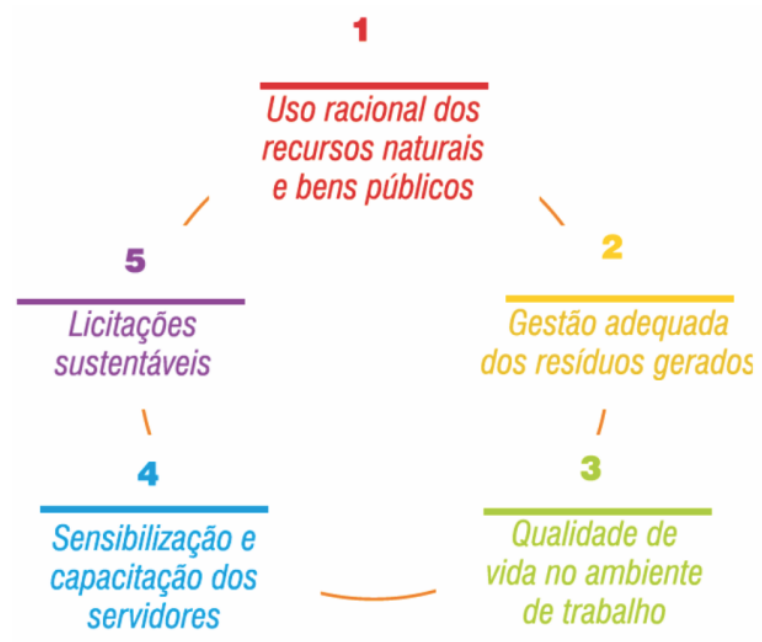

Figura 1. Eixos temáticos da $\mathrm{A} 3 \mathrm{P}$

Fonte: Ministério do Meio Ambiente (2009, p.36)

O primeiro eixo, que aborda o uso racional dos recursos naturais e bens públicos, incentiva usar racionalmente energia, água, madeira, papel, copos plásticos e outros materiais de expediente; o eixo dois lida com a redução do consumo e combate ao desperdício em primeiro lugar, para então buscar a destinação correta do resíduo gerado; o terceiro eixo, sobre a qualidade de vida no ambiente de trabalho, se propõe facilitar e satisfazer as necessidades do trabalhador no desenrolar de suas atividades na organização com ações para o desenvolvimento pessoal e profissional; o eixo que aborda a sensibilização e capacitação dos servidores tenciona a criação e consolidação da consciência cidadã da responsabilidade socioambiental nestes; o último eixo, de licitações sustentáveis, promove a compra de produtos e serviços com responsabilidade socioambiental (MMA, 2009).

A implantação da A3P em uma instituição parte da iniciativa de revisão das posturas, atitudes e práticas internas adotadas pelo órgão interessado (MMA, 2009). Essa iniciativa, conforme o MMA (2009), requer o engajamento individual e coletivo para que haja uma legítima mudança de hábitos, transformando, assim, o discurso teórico em ações palpáveis. Dessa forma, a A3P pode ser tratada como proposta de uma inovação organizacional, onde os colaboradores devem normativamente adotar novas práticas de uso de equipamentos novos e antigos no ambiente de trabalho.

Para o engajamento dos indivíduos nas práticas desejadas pelas empresas, Bitencourt, Azevedo e Froehlich (2013) propõem que o claro posicionamento da organização quanto ao que ela é e seus objetivos permite que seus colaboradores avaliem, de forma mais convicta, quais são as boas práticas e de que forma elas devem ser praticadas, frente a isto propõem-se as lentes das práticas.

\subsection{Teorias das Práticas [TdP]}

Schatzki (2005a) explana que não existe uma abordagem unificada para as práticas e isso se deve à pluralidade de áreas às quais os teóricos e acadêmicos do assunto pertencem e suas 
consequentes diferentes formas de pensar, com pontos convergentes e divergentes entre si. Mesmo diante dessa pluralidade, as considerações sobre as práticas se interligam " [...] na crença de que fenômenos como conhecimento, significado, atividades, ciência, poder, linguagem, instituições sociais e transformações históricas ocorrem no âmbito das práticas e se apresentam como aspectos ou componentes deste campo." (Schatzki, 2005a, p.11, tradução nossa).

Quando aborda o termo práticas, Schatzki (2005c) se refere a atividades humanas organizadas onde qualquer prática se constitui de uma série de ações espaciais e temporais organizadas e amplas. Essas ações podem ser exemplificadas em uma grande variedade de práticas, tais como as políticas, no ato de cozinhar, nas atividades de lazer, e nas práticas religiosas. Schatzki (2005b) ressalta que essas atividades expõem duas dimensões usadas na definição de práticas: atividade e organização. $\mathrm{O}$ autor explana que o termo atividade se reporta à noção de prática como um conjunto de ações realizadas pelas pessoas (performance), e esse mesmo conjunto de ações constituintes de uma prática pode ser compreendido como fazeres e dizeres ou como as ações que esses fazeres e dizeres constituem (Schatzki, 2005b).

O termo organização, consoante Schatzki $(2005 b, 2005 c)$, remete à estruturação do conjunto de ações que compõem uma prática, que se dá por três elementos fundamentais: entendimentos de como fazer as coisas, que se referem ao saber fazer as coisas que estão envolvidos em uma determinada prática; regras, as quais se tratam de formulações explícitas que estabelecem, exigem ou instruem como determinadas ações devem ser executadas, faladas, praticadas; e estruturas teleoafetivas, que consiste em um conjunto de objetivos, usos (das coisas) e até emoções que são aceitáveis ou previstas para os participantes da prática. Trata-se de uma junção da teleologia, que é uma orientação voltada para os fins, com a afetividade, que expressa a importância dada às coisas (Schatzki, 2005b). Ou seja, o complexo estruturante do conjunto de fundamentos constituintes da prática, quais sejam, os entendimentos, as regras e as estruturas teleoafetivas são os elementos que conferem organização aos fazeres e dizeres pertinentes a uma prática (Schatzki, 2005b). Esses fazeres e dizeres são compreensíveis tanto para o agente ou agentes que executam a prática, quanto para observadores em potencial, conforme Reckwitz (2002).

Autores que estudam práticas em consumo sustentável e práticas sustentáveis "operacionalizam" sua análise com três elementos, quais sejam, material, significado e competência/conhecimento prático (Reckwitz, 2002; Schäfer et al., 2018; Shove et al., 2012; Spurling et al., 2013; Süßbauer \& Schäfer, 2018). Para Shove et al. (2012), esses três elementos se apresentam de forma interligada:

a) Materiais, constituídos pelos objetos, pela infraestrutura, pelas ferramentas, pela parte física dos equipamentos e pelo próprio corpo;

b) Significado, que envolve as atividades mentais, as emoções e o conhecimento motivacional;

c) Conhecimento prático, formado pelos entendimentos compartilhados sobre um bom e adequado desempenho e as competências necessárias a esse desempenho.

Baseando-se na obra de Shove et al. (2012), Süßbauer e Schäfer (2018) ilustram a combinação entre os três elementos constituintes da prática (Figura 2): 
Materiais: objetos, infraestrutura, ferramentas,
parte física dos equipamentos e o próprio corpo

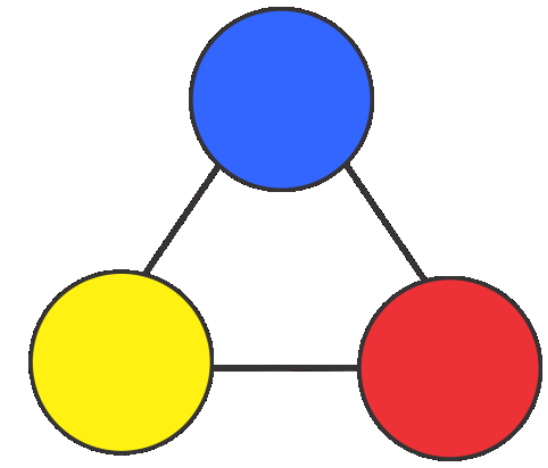

Significado: atividades mentais,

Conhecimento prático: entendimentos emoçőes e o conhecimento motivacional compartilhados sobre um bom e adequado desempenho e as competências necessárias a esse desempenho

Figura 2. Três elementos constituintes da prática

Fonte: Adaptado por Süßbauer e Schäfer (2018, p. 330) da obra de Shove, Pantzar e Watson (2012).

Assim, uma prática social é formada pela interligação entre esses três elementos, que necessariamente devem existir e coexistir para que haja a prática, ademais, essa prática não pode se reduzir a somente um dos elementos (Reckwitz, 2002 como citado em Süßbauer \& Schäfer, 2018). A performance das práticas, segundo Schäfer et al. (2018), depende da coevolução dos elementos que as compõem.

Bitencourt et al. (2013, p. 166) entendem que "[...] as práticas são padrões reconhecidos, os quais, ainda que variem grandemente de acordo com o cenário em que são desempenhados, são reconhecíveis e, pela própria execução, se disseminam e se modificam constantemente, recursivamente.". Essa ideia da possibilidade de mudança das práticas também é compartilhada por Süßbauer e Schäfer (2018), que ilustraram o ciclo de vida de uma prática fundamentando-se em Shove et al. (2012), como pode ser observado na Figura 3:

Proto-próticas:

Conexס̋es năo realizadas

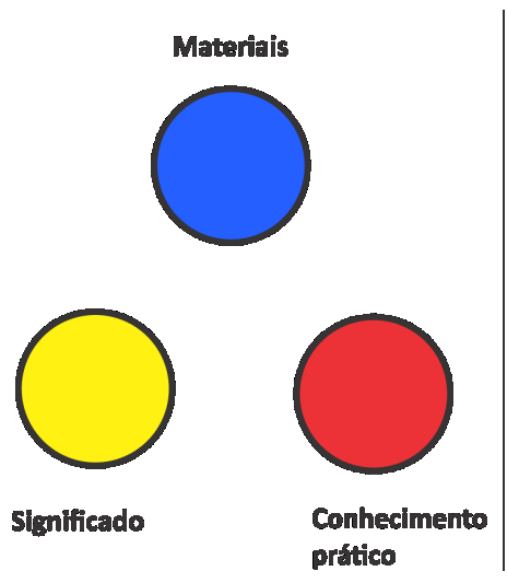

Práticas:

Conexøes realizadas

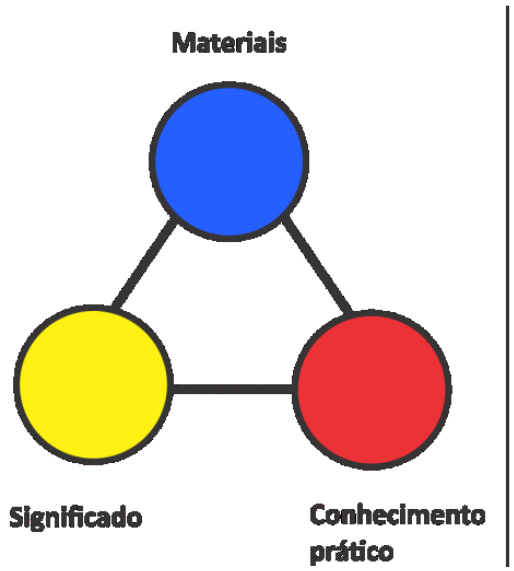

Ex-Practices:

Conexס̋es não mais realizadas

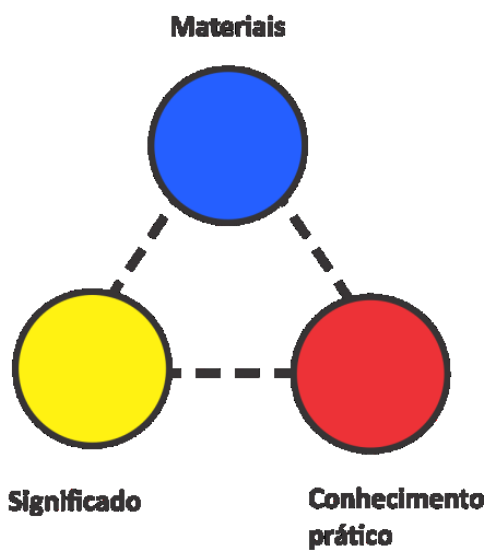

Figura 3. Estágios de vida de uma prática

Fonte: Adaptado por Süßbauer e Schäfer (2018, p. 331) da obra de Shove, Pantzar e Watson(2012). 
Aline Ribeiro Gomes, José Carlos Lázaro da Silva Filho, Áurio Lúcio Leocádio

A "fase" de proto-práticas incorre na existência dos elementos constituintes da prática, embora eles ainda não estejam conectados, o estágio das práticas em si, no qual os elementos se combinam sistematicamente e, por fim, a fase de ex-práticas, na qual os elementos se desconectam uns dos outros (Süßbauer \& Schäfer, 2018).

Salienta-se que a inexistência de um elemento impossibilita mesmo uma proto-prática, isto é, se não houver materialidade (material, infraestrutura), uma prática não pode se desenvolver. $\mathrm{O}$ mesmo ocorre na inexistência de um significado (como sustentabilidade), ou de como realizar a prática (como operar algum equipamento ou procedimento complexo para tal prática). Süßbauer e Schäfer (2018) ressaltam que a propagação do consumo sustentável, como uma atividade significativa no ambiente organizacional aliada ao fornecimento de condições materiais de apoio, e o conhecimento prático são condutas que devem compor uma estratégia sistemática de ecologização das corporações.

Diante do referencial exposto, visando o atendimento do objetivo geral proposto pelo estudo, partiu-se para a definição da metodologia a ser empregada, que será apresentada na seção a seguir.

\section{MÉTODO DE PESQUISA}

Objetivando investigar a adesão dos colaboradores da Nutec às práticas da A3P referentes ao uso da energia promovidas na instituição, usando as lentes das Teorias das Práticas aplicadas por Shove et al. (2012), foi realizada uma pesquisa qualitativa de caráter descritivo, cujo procedimento técnico adotado é o estudo de caso (Yin, 2014). A Nutec foi escolhida por ser um campo onde a Agenda Ambiental na Administração Pública se encontrava em processo de implantação no período de realização do estudo aliado à facilidade de acesso aos espaços físicos, funcionários e registros documentais, uma vez que já se atuava na instituição dois anos antes do início da pesquisa.

A Fundação Núcleo de Tecnologia Industrial do Ceará é uma entidade pública cuja missão é "Desenvolver pesquisas e tecnologias inovadoras e prestar serviços técnicos especializados para o governo, indústria e sociedade, viabilizando soluções tecnológicas para o desenvolvimento sustentável" (Fundação Núcleo de Tecnologia Industrial do Ceará, 2018). Em novembro de 2017, foram designados nove colaboradores da Nutec para integrarem a comissão de implementação da A3P na instituição (Ceará, 2017). Em abril de 2018, foi elaborado o plano de trabalho para estruturar e dar início ao processo de implantação da A3P e, em julho do mesmo ano, celebrou-se o termo de adesão da fundação ao programa (Brasil, 2018).

A obtenção de informações se deu por meio de dados primários, extraídos da realidade estudada (Prodanov \& Freitas, 2013), voltados especificamente para os fins da pesquisa e por meio de dados secundários, explorados em publicações avulsas. Optou-se por uma multiplicidade de técnicas de coletas de dados com o intuito de tentar observar e analisar as práticas sustentáveis referentes ao uso da energia, sob diferentes perspectivas. Hargreaves (2011) frisa que, como as Teorias das Práticas Sociais focam na realização dos fazeres das práticas cotidianas, é demandado o uso de técnicas metodológicas que permitam a observação do que realmente ocorre no desempenho da prática.

Dessa forma, recorreu-se à técnica de observação participante (Martins \& Theóphilo, 2009), que se fundamentou em entrevistas em grupo e conversas informais junto a uma amostra de funcionários da instituição aliadas aos registros do que foi observado em diário de campo para anotações, comentários e reflexões acerca do âmbito estudado (Falkembach, 1987, como citado em Gerhardt \& Silveira, 2009), bem como à investigação documental referente à Nutec.

Os registros efetuados em diário de campo são provenientes da observação participante nos setores financeiro e administrativo, ocorrida no período de maio a outubro de 2018 . O roteiro da entrevista aplicada ao grupo de funcionários seguiu um padrão de questões abertas onde os entrevistados foram estimulados a dissertarem livremente durante toda a sua aplicação. A entrevista ocorreu no final do mês de outubro de 2018 e contou com questionamentos baseados nas práticas de

Revista de Gestão Social e Ambiental - RGSA, São Paulo, v. 14, n. 1, p. 03-17, jan./abr. 2020. 
uso racional de energia promovidas pela instituição. Quanto às conversas informais, estas ocorreram durante todo o período da observação participante.

As publicações avulsas utilizadas como dados secundários são referentes às ações da A3P no tocante ao uso da energia estimuladas no órgão em estudo. Elas se encontram dispostas nas dependências da instituição em cartazes afixados nas paredes, adesivos educativos próximos às tomadas e computadores, displays com panfletos explicativos, bem como e-mails informativos enviados aos funcionários.

Os cartazes afixados chamavam a atenção para a conscientização quanto ao desperdício de energia, os adesivos próximos às tomadas e computadores alertavam para que os funcionários não esquecessem de efetuar o desligamento dos equipamentos, já os displays com panfletos instruíam com exemplos práticos do que pode ser feito para economizar energia, enquanto os e-mails corporativos informavam com frases motivacionais, ilustrações, campanhas de conscientização e dicas contra o desperdício de energia.

Com base nas informações extraídas das publicações avulsas, foram relacionadas as ações da A3P adotadas na Nutec e distribuídas conforme categorização estabelecida na cartilha A3P disponibilizada pelo MMA (2009), presentes na Figura 4:

\begin{tabular}{|c|l|l|l|}
\hline $\begin{array}{c}\text { Eixo da } \\
\text { A3P }\end{array}$ & $\begin{array}{c}\text { Ação da A3P } \\
\text { adotada pelo } \\
\text { órgão }\end{array}$ & \multicolumn{1}{c|}{$\begin{array}{c}\text { Práticas } \\
\text { observadas }\end{array}$} & \multicolumn{1}{c|}{$\begin{array}{c}\text { Novas Práticas “promovidas"/propostas pela } \\
\text { instituição }\end{array}$} \\
\hline \multirow{2}{1.\text{Uso}}{$\begin{array}{c}\text { racional } \\
\text { dos } \\
\text { recursos } \\
\text { naturais e } \\
\text { bens } \\
\text { públicos }\end{array}$} & $\begin{array}{c}\text { Uso racional de } \\
\text { energia }\end{array}$ & $\begin{array}{l}\text { 1. Ligar e desligar } \\
\text { as luzes }\end{array}$ & $\begin{array}{l}\text { Desligar as lâmpadas dos ambientes que não estiverem } \\
\text { em uso. }\end{array}$ \\
\cline { 3 - 4 } & ar condicionado & $\begin{array}{l}\text { Ligar os ares condicionados uma hora após o início do } \\
\text { expediente, desligá-los uma hora antes do final do } \\
\text { expediente. }\end{array}$ \\
\cline { 3 - 4 } & & $\begin{array}{l}\text { 3. Ligar e desligar o o } \\
\text { computador }\end{array}$ & $\begin{array}{l}\text { Desligar o computador quando não estiver em uso, } \\
\text { deixar o computador em modo stand by quando passar } \\
\text { mais de cinco minutos sem utilizá-lo. }\end{array}$ \\
\hline
\end{tabular}

Figura 4. Relação das práticas da A3P referentes ao uso racional de energia promovidas pela Nutec

Fonte: Elaboração própria

Com as práticas alusivas ao uso racional de energia elencadas, buscou-se verificar se estas possuem material, significado e conhecimento prático/competência, visando identificar se existe a interligação entre esses três elementos, condição necessária para que haja a prática, conforme 0 referencial teórico abordado (Reckwitz, 2002; Shove et al., 2012; Spurling et al., 2013; Süßbauer \& Schäfer, 2018), conforme explicitado na Figura 5:

\begin{tabular}{|c|c|c|c|c|c|}
\hline \multirow[b]{2}{*}{$\begin{array}{l}\text { Eixo } \\
\text { da } \\
\text { A3P }\end{array}$} & \multirow[b]{2}{*}{$\begin{array}{c}\text { Ação da } \\
\text { A3P } \\
\text { adotada } \\
\text { pelo } \\
\text { órgão }\end{array}$} & \multirow[b]{2}{*}{$\begin{array}{c}\text { Práticas } \\
\text { observadas }\end{array}$} & \multicolumn{3}{|c|}{ Elementos } \\
\hline & & & $\begin{array}{c}\text { Material } \\
\text { (Observação em campo } \\
\text { se existem materiais, se } \\
\text { eles estão disponíveis, } \\
\text { são de fácil acesso, de } \\
\text { forma a permitir a } \\
\text { ocorrência da prática) }\end{array}$ & $\begin{array}{c}\text { Significado } \\
\text { (Estruturação dos } \\
\text { questionamentos } \\
\text { para verificar se a } \\
\text { prática tem um } \\
\text { significado ambiental } \\
\text { / sustentável) }\end{array}$ & $\begin{array}{l}\text { Conhecimento prático / } \\
\text { Competência } \\
\text { (Estruturação dos } \\
\text { questionamentos para } \\
\text { verificar se o praticante sabe } \\
\text { como fazer a prática) }\end{array}$ \\
\hline \multirow{2}{*}{ 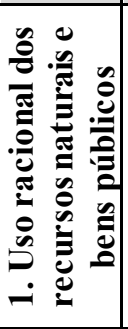 } & \multirow{2}{*}{$\begin{array}{l}\text { Uso } \\
\text { racional } \\
\text { de } \\
\text { energia }\end{array}$} & $\begin{array}{l}\text { 1. Ligar e } \\
\text { desligar as } \\
\text { luzes }\end{array}$ & $\begin{array}{c}\text { Existência de } \\
\text { interruptores de fácil } \\
\text { acesso para o } \\
\text { desligamento das luzes. }\end{array}$ & $\begin{array}{c}\text { Significado } \\
\text { ambiental do ato de } \\
\text { apagar as luzes. }\end{array}$ & $\begin{array}{l}\text { Os entrevistados sabem } \\
\text { como proceder para } \\
\text { ligar/desligar as luzes. }\end{array}$ \\
\hline & & $\begin{array}{c}\text { 2. Ligar e } \\
\text { desligar o ar } \\
\text { condicionado }\end{array}$ & $\begin{array}{c}\text { Fácil acesso aos botões } \\
\text { de ligar/desligar e } \\
\text { regulagem dos ares } \\
\text { condicionados. }\end{array}$ & $\begin{array}{c}\text { Significado } \\
\text { ambiental do ato de } \\
\text { desligar o ar } \\
\text { condicionado. }\end{array}$ & $\begin{array}{c}\text { Os entrevistados sabem } \\
\text { como proceder para ligar / } \\
\text { desligar / regular o ar } \\
\text { condicionado. }\end{array}$ \\
\hline
\end{tabular}

Revista de Gestão Social e Ambiental - RGSA, São Paulo, v. 14, n. 1, p. 03-17, jan./abr. 2020. 
Aline Ribeiro Gomes, José Carlos Lázaro da Silva Filho, Áurio Lúcio Leocádio

\begin{tabular}{|c|c|c|c|c|c|}
\hline & $\begin{array}{c}\text { 3. Ligar e } \\
\text { desligar o } \\
\text { computador }\end{array}$ & $\begin{array}{c}\text { Fácil acesso para o } \\
\text { desligamento de } \\
\text { computadores. }\end{array}$ & $\begin{array}{c}\text { Significado } \\
\text { ambiental do ato de } \\
\text { desligar o } \\
\text { computador. }\end{array}$ & $\begin{array}{c}\text { Os entrevistados sabem } \\
\text { como proceder para } \\
\text { ligar/desligar o computador } \\
\text { ou deixar no modo stand by. }\end{array}$ \\
\hline
\end{tabular}

Figura 5. Relação dos elementos das práticas observados e estruturas dos questionamentos realizados

Fonte: Elaboração própria.

A verificação desses elementos se deu por meio da triangulação de fontes de dados recomendada por Yin (2014), utilizando-se da convergência das evidências extraídas de observações (direta e participante) na rotina organizacional da Nutec aliada às conversas informais, publicações avulsas, além da condução de entrevista em grupo junto aos funcionários.

A fase inicial do encontro com o grupo de funcionários, anterior à aplicação do roteiro de entrevista, se constituiu de apresentação explicativa sobre a pesquisa, entrega e assinatura do termo de consentimento e participação. A entrevista foi conduzida em uma roda de conversa na qual os entrevistados receberam estímulos para que conversassem abertamente sobre as suas opiniões referentes aos tópicos considerados no roteiro e foi incentivado para que todos falassem conforme se sentissem à vontade. Já a fase final, posterior à aplicação da entrevista, contou com conversas informais com os participantes do grupo que espontaneamente acrescentaram informações referentes ao que foi discutido no encontro.

Os entrevistados foram codificados para preservar o anonimato e facilitar a apresentação dos trechos das entrevistas utilizados na demonstração dos resultados. Utilizou-se da letra "E" seguida de um número, que foi de um a quatro, correspondente ao quantitativo de entrevistados e se encontram explícitos na Figura 6 com seus respectivos perfis demográficos:

\begin{tabular}{|c|c|c|c|c|c|}
\hline Código & Idade & Sexo & Nível de escolaridade & Estado civil & $\begin{array}{c}\text { Tempo na } \\
\text { organização }\end{array}$ \\
\hline E1 & 23 & Masculino & ensino médio completo & casado & 5 anos \\
\hline E2 & 23 & Feminino & superior incompleto & solteira & 1 ano \\
\hline E3 & 56 & Feminino & ensino médio completo & solteira & 1 ano \\
\hline E4 & 37 & Feminino & ensino médio completo & casada & 8 anos \\
\hline
\end{tabular}

Figura 6. Perfil demográfico dos entrevistados no grupo focal

Fonte: Elaboração própria

Os dados obtidos na entrevista foram transcritos e, com as informações coletadas na observação participante, foram tratados e analisados conforme análise categorial proposta por Bardin (2014, p. 199), que se dá "[...]por operações de desmembramento do texto em unidades, em categorias segundo reagrupamentos analógicos.". As categorias nas quais os dados coletados foram organizados são constituídas pelos elementos material, significado e conhecimento prático/competência constituintes das práticas relacionadas ao uso racional de energia. Tais categorias foram estabelecidas, a priori, com base no referencial estudado sobre Teorias das Práticas e obedecendo a categorização de ações sustentáveis estimuladas pelo Ministério do Meio Ambiente junto aos órgãos públicos proveniente da cartilha A3P (MMA, 2009).

\section{ANÁLISE E DISCUSSÃo DOS RESULTADOS}

Ante os dados coletados na pesquisa, tem-se adiante uma análise das práticas da A3P referentes ao uso da energia promovidas na Nutec, usando as lentes das Teorias das Práticas aplicadas por Shove et al. (2012).

Inicialmente, os dados obtidos foram categorizados conforme as três práticas alusivas ao uso da energia identificadas na instituição: (i) Desligar as lâmpadas dos ambientes que não estiverem em uso; (ii) Ligar os ares condicionados uma hora após o início do expediente e desligá-los uma 
hora antes do final do expediente e (iii) Desligar o computador quando este não estiver em uso, deixá-lo em modo stand by quando passar mais de cinco minutos sem utilizá-lo.

No tocante à primeira prática, tendo como base as informações coletadas em campo e destacadas nos trechos dispostos na Figura 7, foi constatado que o ato de desligar as lâmpadas do ambiente de trabalho dos entrevistados apresenta materialidade comprometida, já que, dos quatro interruptores existentes, um deles, que compete às lâmpadas centrais dos setores explorados, não se encontra de fácil acesso para alguns dos praticantes da ação. $\mathrm{O}$ acesso a este interruptor encontra-se com uma barreira material (um móvel), o que impede que pessoas mais baixas possam atuar como praticantes do ato de acender e apagar as luzes. Süßbauer e Schäfer (2018) afirmam que, para ecologizar o ambiente de trabalho, se devem incluir condições materiais que deem suporte a essa ação.

Por meio de seus relatos, os entrevistados demonstram que entendem que esta prática, em termos ambientais, se relaciona com a economia de energia (transparecendo em seus discursos pelo emprego dos termos "economicidade" e "economia de energia") e a preservação do meio ambiente. Para Dantsiou e Sunikka-Blank (2015), o entendimento sobre a energia é importante para verificar a capacidade de economizá-la. Dessa forma, a prática em análise apresenta significado ambiental/sustentável para os entrevistados.

Já em termos de conhecimento prático, todos demonstraram saber onde ficam as tomadas, por meio de suas afirmações, além de terem o entendimento de como procederem para manusear os interruptores. Em vista dos achados referentes aos elementos da prática de desligar as lâmpadas dos ambientes que não estiverem em uso, considera-se que essa prática se comporta de forma afetada, pois nem todos os seus elementos componentes encontram-se interconectados (Süßbauer \& Schäfer, 2018).

\begin{tabular}{|c|c|c|c|}
\hline \multirow{2}{*}{$\begin{array}{l}\text { Práticas } \\
\text { promovida } \\
\text { s na } \\
\text { NUTEC }\end{array}$} & \multicolumn{3}{|c|}{ Elementos constituintes das práticas } \\
\hline & Material & Significado & \begin{tabular}{|c} 
Conhecimento \\
prático/Competênc \\
ia
\end{tabular} \\
\hline $\begin{array}{c}\text { 1. Desligar as } \\
\text { lâmpadas dos } \\
\text { ambientes que } \\
\text { não estiverem } \\
\text { em uso. }\end{array}$ & $\begin{array}{l}\text { DC: Três dos quatro } \\
\text { interruptores do setor explorado } \\
\text { são de fácil acesso. Um deles, } \\
\text { que é o que apaga as lâmpadas } \\
\text { centrais, se encontra acima de } \\
\text { um armário, dificultando o ato } \\
\text { de acender e apagar as luzes } \\
\text { para pessoas de estatura abaixo } \\
\text { de } 1,55 \text { metros. }\end{array}$ & $\begin{array}{l}\text { E2: [...] diminui os custos da } \\
\text { empresa em relação à conta de } \\
\text { energia, economicidade, mas } \\
\text { também pensando na preservação } \\
\text { do meio ambiente. } \\
\text { E1: } \\
\text { E3: } \quad \text { Economia de energia } \\
\text { E4: }\end{array}$ & $\begin{array}{l}\text { E1: } \operatorname{Sim}((\text { têm } \\
\text { E3: conhecimento } \\
\text { E4: do local das } \\
\quad \text { tomadas)) } \\
\text { E2: } \text { Sim, } \text { eu } \text { sei. ((onde } \\
\text { ficam as tomadas)) }\end{array}$ \\
\hline $\begin{array}{c}\text { 2. Ligar os } \\
\text { ares } \\
\text { condicionados } \\
\text { uma hora } \\
\text { após o início } \\
\text { do } \\
\text { expediente, } \\
\text { desligá-los } \\
\text { uma hora } \\
\text { antes do final } \\
\text { do } \\
\text { expediente. }\end{array}$ & $\begin{array}{l}\text { DC: O processo de ligar e } \\
\text { desligar os ares condicionados e } \\
\text { a regulagem da temperatura é } \\
\text { feito mediante dois controles } \\
\text { disponíveis em dispositivos } \\
\text { acoplados na parede, o que } \\
\text { significa que é de fácil acesso. } \\
\text { No entanto, às vezes, um dos } \\
\text { funcionários esquece o controle } \\
\text { em cima da própria mesa. As } \\
\text { portas e janelas dos ambientes } \\
\text { são fechadas quando os ares } \\
\text { condicionados são ligados. }\end{array}$ & \begin{tabular}{|l|} 
E4: Eu acho que o maior fator foi \\
isso aí, a questão da:, da \\
economia. \\
E1: Que aí não vai acabar os \\
recursos naturais, sem \\
economizar a energia, acaba mais \\
rápido, né? \\
E2: [...] também causa econo/, é:: a \\
preservação do equipamento. \\
Porque quanto você consumir \\
menos desses equipamentos, eu \\
acredito que seja melhor.
\end{tabular} & 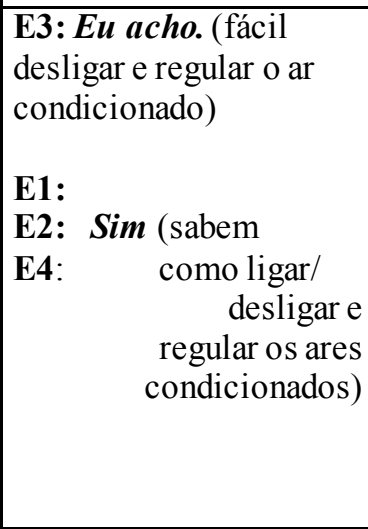 \\
\hline $\begin{array}{c}\text { 3. Desligar o } \\
\text { computador } \\
\text { quando não } \\
\text { estiver em } \\
\text { uso, deixá-lo }\end{array}$ & $\begin{array}{l}\text { DC: Os botões de ligamento e } \\
\text { desligamento de computadores } \\
\text { são de acesso fácil aos seus } \\
\text { usuários. Os computadores são } \\
\text { programados pelo setor de } \mathrm{TI}\end{array}$ & $\begin{array}{l}\text { E3: Também, né, economia, né? } \\
\text { Sem dúvida. ((Todos fazem sinal } \\
\text { afirmativo com a cabeça } \\
\text { concordando com E3)) } \\
\text { E2: [...] desligar o computador, pro }\end{array}$ & $\begin{array}{l}\text { E2: Stand by é só } \\
\text { desligar a tela e e } \\
\text { bloquear, né? } \\
\text { E1:É E desligar, desliga } \\
\text { total, né? }\end{array}$ \\
\hline
\end{tabular}

Revista de Gestão Social e Ambiental - RGSA, São Paulo, v. 14, n. 1, p. 03-17, jan./abr. 2020. 
Aline Ribeiro Gomes, José Carlos Lázaro da Silva Filho, Áurio Lúcio Leocádio

\begin{tabular}{|c|c|c|c|}
\hline $\begin{array}{c}\text { em modo } \\
\text { stand by } \\
\text { quando passar } \\
\text { mais de cinco } \\
\text { minutos sem } \\
\text { utilizá-lo. }\end{array}$ & $\begin{array}{l}\text { para entrarem no modo } \\
\text { descanso de tela após } 10 \\
\text { minutos sem utilização, caso os } \\
\text { colaboradores esqueçam de } \\
\text { deixar no modo stand by. }\end{array}$ & $\begin{array}{l}\text { meio ambiente, talvez seja a } \\
\text { preservação do equipamento pra } \\
\text { não ter que comprar [...] } \\
\text { equipamentos de informática que } \\
\text { não funcionam mais e não tem um } \\
\text { descar/ um descarte correto pra } \\
\text { eles, consequentemente pode é: } \\
\text { poluir o meio ambiente. Então eu } \\
\text { acho que tá nessa relação também. }\end{array}$ & $\begin{array}{l}\text { E3: Até o estabilizador e } \\
\text { tudo. } \\
\text { E3: [...] Na hora do } \\
\text { almoço, por exemplo, } \\
\text { eu deixo no stand by. } \\
\text { E3: Mas desliga tudo } \\
\text { quando já vai embora, } \\
\text { né? } \\
\text { E1: É. }\end{array}$ \\
\hline
\end{tabular}

Figura 7. Relação das práticas da A3P promovidas na Nutec referentes ao uso racional de energia e trechos das fontes primárias relacionadas às práticas abordadas

DC: Diário de Campo

Fonte: Elaboração própria

A segunda prática (Figura 7), relacionada ao ligamento e desligamento dos ares condicionados e regulagem da temperatura, possui mecanismos de materialidade que permitem facilmente a ocorrência dessa prática, embora o comportamento de um dos colaboradores, às vezes, a dificulte. Foi verificado no momento da observação participante que as portas e janelas dos ambientes são fechadas sempre que os ares-condicionados são ligados. O significado ambiental dessa prática é visto pelos entrevistados como uma forma de economia de energia, além da preservação do equipamento estar relacionada de forma positiva ao meio ambiente. Assim, a prática em questão se enquadra na ideia proposta por Shove et al. (2012), onde as práticas consistem em integrações ativas de material, competência e significado.

A prática que trata do ligamento e desligamento do computador e sua manipulação para o modo stand by apresenta elementos materiais favoráveis e, mesmo no caso de esquecimento em deixar no modo de descanso, os aparelhos encontram-se programados para entrar nesse modo após dez minutos sem utilização. Foi atribuído a essa prática o significado ambiental de economia, preservação do equipamento para reduzir o consumo, além do incorreto descarte estar relacionado à poluição do meio ambiente. Os entrevistados apresentam noção de como exercer essa prática, inclusive explicam o momento ideal e as diferenças entre ligar, desligar e deixar no modo stand by. Por conseguinte, conforme Shove et al., 2012, a referida prática se encontra estabelecida, pois seus elementos se encontram em relação de interdependência. Dessa forma, ficou exposto em quais estágios de vida de uma prática (Shove et al., 2012 como citado em Süßbauer \& Schäfer, 2018) as práticas promovidas pela instituição no tocante ao uso de energia se encontram (Figura 8): 


\section{Desligar as lâmpadas dos ambientes que nfôo estiverem em uso.}

Proto-prátlca: Conexăo ainda næa realizada.

Material: nem todos os interruptores såo de fácil acesso

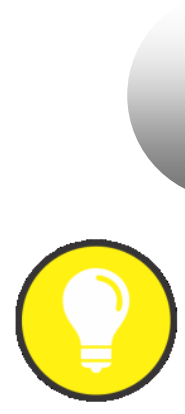

Significado: economia de energia, preservaçäo do meio ambiente

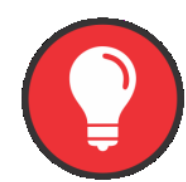

Conhecimento prático: entendimento de como proceder para apagar as luzes estabelecido

\section{Ligar os ares condicionados uma hora após o início do expediente, desligh́-los uma hora anteł do final do expediente.}

Prática: Conexfóo realizada.

Material: controles dos ares condicionados såo de fácil acesso

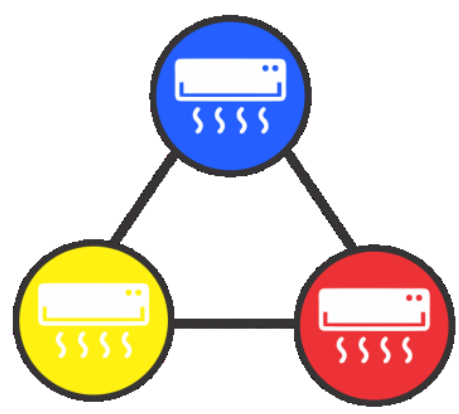

Signifleado: economia de energia, preservaçăo do equipamento $=$ relaçẵo positiva com o meio ambiente
Conhecimento prítico: entendimento de como ligar e desligar os ares condicionados realizado

\title{
3. Desligar o computador quando nto eattver em uso, deixn- lo em modo stand by quando passar maia de einco minutos sem utllixá-lo.
}

\section{Prática: Conexalo realizada.}

Materlal: botð̋es de ligar / desligar sắo de fảcil acesso, os computadores sấo programados para entrarem em modo de espera

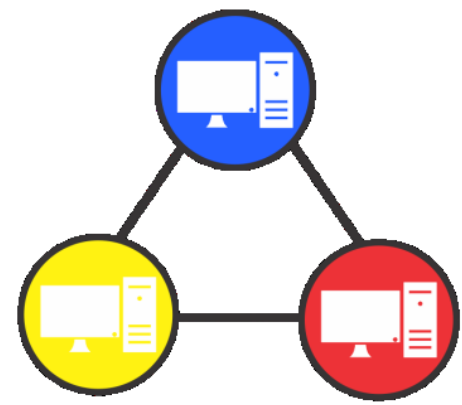

\begin{abstract}
Significado: economia, preservaçto do equipamento é vista como reduçăo de consumo, descarte incorreto $=$ poluiçẩo do meio ambiente

Conhecimento prático: entendimento de como proceder para desligar 0 computador e deixá-lo no modo stand by
\end{abstract}

Figura 8. Estágios de vida das práticas referentes ao uso racional de energia

Fonte: Elaboração própria baseado em adaptação de Süßbauer e Schäfer (2018) da obra de Shove,

Pantzar e Watson(2012).

Os resultados da análise demonstram que, das três práticas referentes ao uso racional da energia detectadas na pesquisa de campo, uma demonstra deficiência do elemento material, o que impede a concretização dessa prática e a enquadra na fase de proto-prática, enquanto as outras duas práticas apresentam os três elementos constituintes das práticas e, assim, elas apresentam todos os elementos necessários para a conexão dos elementos e o, consequente, estabelecimento da prática. Dessa forma, os resultados enfatizam a necessidade de se trabalhar o elemento material para que a prática sustentável promovida que se encontra comprometida possa se estabelecer na instituição. 


\section{CONSIDERAÇÕES FINAIS}

A averiguação dos elementos das práticas foi um dos procedimentos utilizados para atender o objetivo principal deste estudo, de investigação da adesão dos colaboradores da Nutec às práticas da A3P referentes ao uso racional da energia promovidas na instituição, usando as lentes das Teorias das Práticas aplicadas por Shove et al. (2012). Por meio de técnicas da análise qualitativa, direcionou-se a pesquisa pela identificação e categorização das práticas socioambientais dentro do uso do recurso energia, que pertence ao eixo 1 da A3P correspondente ao uso racional dos recursos naturais e bens públicos.

Os resultados da etapa de catalogação e categorização das práticas socioambientais identificadas foram evidenciados por meio de um quadro que embasou o roteiro da entrevista aplicada e os tópicos considerados na observação participante. A análise permitiu verificar que, das três práticas referentes ao recurso energia elencadas, uma apresenta o elemento material comprometido.

Esta pesquisa busca dar sua contribuição para as pesquisas desenvolvidas no tocante às práticas de uso do recurso energia pela ótica das Teorias das Práticas. O modelo, aplicado por Shove et al. (2012), poderá ser utilizado como referência de análise em novos estudos de práticas socioambientais. Ademais, este trabalho contribuiu para que se lançasse uma nova perspectiva teórica de análise da adesão organizacional às práticas da $\mathrm{A} 3 \mathrm{P}$, uma vez que, em investigação preliminar em bases de dados acadêmicas de trabalhos com o mesmo propósito, identificou-se que as Teorias das Práticas ainda não haviam sido utilizadas.

Essa diferente proposição metodológica permitiu ir além da constatação de quais práticas socioambientais foram adotadas no ambiente organizacional: ela também possibilitou detectar os possíveis entraves a serem superados para que se amplie essa adesão. Outra contribuição teórica deste estudo a ser destacada, reside no entendimento de mecanismos que possam propiciar a redução de padrões de consumo em práticas sociais.

No campo das implicações gerenciais, pretende-se também contribuir na identificação de fatores a serem trabalhados pelo órgão estudado para que a prática socioambiental de uso do recurso energia, que ainda não se comporte em sua plenitude, atinja o estágio de prática. É necessária a tomada de decisões gerenciais que culminem na melhoria e/ou no estabelecimento de elementos materiais em uma de suas práticas.

Propõem-se periódicas checagens dos elementos constituintes das práticas promovidas pela instituição para que se evite que a ação da A3P em estágio de prática incorra na fase de ex-prática, além de se estender essa checagem para outras práticas socioambientais promovidas.

Nas limitações, tem-se a realização da entrevista a uma categoria muito específica de funcionários da instituição, o que pode restringir a análise à visão do grupo investigado. Outro fator limitante foi a realização da análise de somente um dos eixos da A3P, já que ela apresenta cinco eixos no total.

Sugere-se a replicação da metodologia para análise do comportamento dos elementos constituintes das práticas em diferentes organizações públicas. Pode-se explorar também o comportamento dos elementos das práticas sustentáveis nos outros eixos da $\mathrm{A} 3 \mathrm{P}$. Ou ainda, num estudo com um público mais amplo, buscar analisar o comportamento das práticas sustentáveis em diferentes categorias demográficas.

\section{REFERÊNCIAS}

Avelino, F., \& Wittmayer, Julia M. (2016). Shifting power relations in sustainability transitions: a multi-actor perspective. Journal of Environmental Policy \& Planning, 18(5), 628-649.

Bardin, L. (2014). Análise de conteúdo (5a ed). Lisboa: Edições 70. 
Teorias das práticas: análise da adoção de práticas socioambientais em um programa público

Bispo, M. (2013). Estudos baseados em prática: conceitos, história e perspectivas. Revista Interdisciplinar de Gestão Social, 2(1), 13-33.

Bitencourt, C., Azevedo, D. \& Froehlich, C. (2013). Na trilha das competências: caminhos possíveis no cenário das organizações. Porto Alegre: Bookman Editora.

Bourdieu, P. (2011). Razões práticas: sobre a teoria da ação (11 ed.). Campinas, SP: Papiprus. Brasil. Extrato de Adesão, de 31 de julho de 2018. (2018). Diário Oficial da União. Seção 3, (146), 126.

Ceará. Portaria n ${ }^{\circ} 111 / 2017$, de 20 de novembro de 2017. (2017). Designa colaboradores para integrarem a Comissão de implantação da Agenda Ambiental na Adminis tração Pública - A3P. Diário Oficial do Estado. Série 3, Ano IX, (215), 13. Fortaleza, CE, 20 nov. 2017.

Cohen, M. J., Brown, H. S., \& Vergragt, P. J. (Eds.). (2013). Advances in ecological economics. innovations in sustainable consumption: New Economics, Socio-technical Transitions and Social Practices. Cheltenham UK: Edward Elgar.

Dantsiou, D., \& Sunikka-Blank, M. (2015). Why does energy use feedback not work in workplaces? Insights from social practice theory. In Proceedings of the Eceee.

Federal, B. S. (1995). Conferência das Nações Unidas sobre meio ambiente e desenvolvimento: a Agenda 21. Brasília: Coordenação de Publicações

Fundação Núcleo de Tecnologia Industrial do Ceará (2018). Identidade Organizacional. Recuperado em 12 outubro, 2018, de http://www.nutec.ce.gov.br/identidade-organizacional/

Gerhardt, T. E. \& Silveira, D. T. (2009). Métodos de pesquisa. Porto Alegre: Editora da UFRGS.

Gherardi, S. (2013). How to conduct a practice-based study: problems and methods. Cheltenham: Edward Elgar Publishing.

Giddens, A. (1984). Constitution of society: outline of the theory of structuration. Berkeley: University of California Press.

Grin, J., Rotmans, J., \& Schot, J. W. (Eds.). (2011). Routledge studies in sustainabilitytransitions. Transitions to sustainable development: new directions in the study of long term transformative change. New York, NY: Routledge, Taylor \& Francis Group.

Hargreaves, T. (2011). Practice-ing behaviour change: applying social practice theory to proenvironmental behaviour change. Journal of Consumer Culture, 11(1), 79-99.

Martins, G. A. \& Theóphilo, C. R. (2009). Metodologia da investigação científica para ciências sociais aplicadas (2 $2^{\mathrm{a}}$ ed). São Paulo: Atlas.

Ministério do Meio Ambiente (2009). Cartilha A3P: Agenda ambiental na administração pública. Brasília: MMA. Recuperado em 29 julho, 2018, de http://www.mma.gov.br/estruturas/a3p/_arquivos/cartilha_a3p_36.pdf

Ministério do Meio Ambiente (2011). Plano de Ação para Produção e Consumo SustentáveisPPCS. Brasília: MMA. Recuperado em 29 julho, 2018, de

http://www.mma.gov.br/responsabilidade-socioambiental/producao-e-consumo-sustentavel/planonacional

Nicolini, D. (2012). Practice theory, work, and organization: An introduction. OUP Oxford.

Nicolini, D. (2017). Practice theory as a package of theory, method and vocabulary: Affordances and limitations. In Methodological reflections on practice oriented theories, 19-34). Springer, Cham. 
Aline Ribeiro Gomes, José Carlos Lázaro da Silva Filho, Áurio Lúcio Leocádio

Palhares, J. C. P., Oliveira, V. B. V., Freire, M., Jr., Cerdeira, A. L., \& Prado, H. A. (2018).

Consumo e produção responsáveis: contribuições da Embrapa. Brasília: Embrapa.

Programa das Nações Unidas para o Meio Ambiente (2012). ABC do CPS: esclarecendo conceitos sobre consumo e produção sustentável. Paris: Pnuma.

Prodanov, C. C. \& Freitas, E. C. (2013) Metodologia do trabalho científico: métodos e técnicas de pesquisa e do trabalho acadêmico (2a ed). Novo Hamburgo: Freevale.

Reckwitz, A. (2002). Toward a theory of social practices: a development in culturalist theorizing. European journal of social theory, 5(2), 243-263.

Rosa, L. A. B. da, Gomes, C. M., Barbieri, L. C., Rodrigues, M. C. M., \& Kneipp, J. M. (2019). Agenda ambiental na administração pública (a3p): uma análise em uma instituição pública federal do rio grande do sul. Revista Gesto: Revista de Gestão Estratégica de Organizações, 7, 85.

Schäfer, M., Hielscher, S., Haas, W., Hausknost, D., Leitner, M., Kunze, I. \& Mandl, S. (2018). Facilitating low-carbon living? A comparison of intervention measures in different communitybased initiatives. Sustainability, 10(4), 1047, 2018.

Schatzki, T. R. (2005a). Introduction: practice theory. In: T. Schatzki, K. Cetina \& E. Von Savigny. (Orgs.). The practice turn in contemporary theory. London: Routledge.

Schatzki, T. R. (2005b). Practice mind-ed orders. In: T. Schatzki, K. Cetina \& E. Von Savigny. (Orgs.). The practice turn in contemporary theory. London: Routledge.

Schatzki, T. R. (2005c). Peripheral vision: the sites of organizations. Organization Studies. 26(3) 465-484 Recuperado em 02 abril, 2018 de https://doi.org/10.1177/0170840605050876.

Seebode, D., Jeanrenaud, S., \& Bessant, J. (2012). Managing innovation for sustainability. R\&D Management, 42, 195-206.

Shove, E., Pantzar, M. \& Watson, M. (2012). The dynamics of social practice: everyday life and how it changes. California: Sage.

Spaargaren, G. (2013). A cultural dimension of sustainable consumption practices: An exploration on theory and policy. In M. J. Cohen, H. S. Brown, \& P. J. Vergragt (Eds.), Advances in Ecological Economics. Innovations in Sustainable Consumption: New Economics, Socio-technical Transitions and Social Practices, 229-251. Cheltenham UK: Edward Elgar.

Spaargaren, G. (2011). Theories of practices: agency, technology, and culture: exploring the relevance of practice theories for the governance of sustainable consumption practices in the new world-order. Global Environmental Change, 21(3) 813-822.

Spurling, N., Mcmeekin, A., Shove, E., Southerton, D. \& Welch, D. (2013). Interventions in practice: re-framing policy approaches to consumer behaviour. 2013. Recuperado em 08 outubro, 2018, de http://eprints.lancs.ac.uk/id/eprint/85608

Süßbauer, E. \& Schäfer, M. (2018). Greening the workplace: conceptualising workplaces as settings for enabling sustainable consumption. International Journal of Innovation and Sustainable Development, 12(3), 327-349.

Warde, A. (2005). Consumption and theories of practice. Journal of Consumer Culture, 5(2), 131153. Recuperado em 21 janeiro, 2019, de http://doi:10.1177/1469540505053090

Yin, R. K. (2014). Case study research: design and methods. (5a ed). California: Sage. 